\title{
The Effect of Drug Abstinence Program on Memory Functioning of Heroin Addicts
}

\author{
Sepideh Aryanfard ${ }^{1}$, Fereshteh Rahimzadeh ${ }^{2,3}$, Maryam Moghani-Lankarani', ${ }^{3}$, Rozainee Khairudin ${ }^{1}$, Yahaya Mahamood ${ }^{1}$, \\ Shervin Assari ${ }^{4,5}$,* \\ ${ }^{1}$ School of Psychology and Human Development, National University of Malaysia, Selangor, Malaysia \\ ${ }^{2}$ Medicine and Health Promotion Institute, Tehran, Iran \\ ${ }^{3}$ Universal Network for Health Information Dissemination and Exchange (UNHIDE), Tehran, Iran \\ ${ }^{4}$ Department of Psychiatry, University of Michigan, Ann Arbor, USA \\ ${ }^{5}$ Center for Research on Ethnicity, Culture and Health, School of Public Health, University of Michigan, Ann Arbor, USA
}

*Corresponding Author: Shervin Assari, MD, Research Investigator, Department of Psychiatry, University of Michigan, 4250 Plymouth Rd., Ann Arbor, MI 48109-2700, USA. Email: assari@umich.edu

\begin{abstract}
Introduction: Most of our knowledge regarding the link between opioid dependence and poor cognitive functioning is derived from cross sectional studies. This longitudinal study measured the change in memory functioning following complete abstinence among individuals with heroin dependence.

Methods: Using a before-after design, this study followed 30 adults with heroin dependence from entry to completion of an abstinence program (cold Turkey method). We collected data on demographic factors and drug use variables. Memory was measured using the Wechsler Memory Scale. Using the paired t test, we compared different domains of memory functioning (i.e. personal information, orientation, mental control, logical memory, number repetition, visual memory, associative learning and memory quotient) before and after abstinence.

Results: There was a significant improvement in memory functioning on orientation, mental control, logical memory, number repetition, visual memory, association learning and memory quotient following completion of the abstinence program. The improvement, however, was not statistically significant for memory on personal information.

Conclusion: This study documented improvement of memory functioning among heroin dependent adults following complete abstinence (cold turkey method). Further research is needed on the effect of heroin abstinence on memory functioning.
\end{abstract}

Keywords: Memory, Heroin, Heroin Dependence, Heroin Dependence/Rehabilitation, Opioid-Related Disorders, Substance Dependence Disorders

Article History: Received: 25 Mar. 2015; Accepted: 13 May. 2015; Online Published: 24 Aug. 2015

Cite this article as: Aryanfard S, Rahimzadeh F, Moghani Lankarani M, Khairudin R, Mahamood Y, Assari S. The effect of drug abstinence program on memory functioning of heroin addicts. Int J Travel Med Glob Health. 2015;3(3):115-8.

\section{Introduction}

The memory function is essential for the performance of daily activities $[1,2]$. Memory is also relevant for drug use treatment programs. Better memory functioning at baseline has been shown to predict better outcomes following drug use treatment $[3,4]$ namely lower relapse and early drop-outs [5]. Immediate improvement in memory function following drug treatment is also predictive of long-term drug treatment outcomes [6].

Despite a large body of literature which links opioid dependence to impaired memory functioning [7], it is not clear whether drug use treatment improves memory functioning or not [8]. Most studies that have linked drug abstinence to better memory functioning have used cross sectional designs [4, 8-13]. Thus, prospective studies are still needed to determine if drug abstinence improves memory functioning or not.

To the best of our knowledge, there is no published evidence in the link between memory functioning when the drug of dependence is heroin [14] and when the abstinence method is cold Turkey. The Cold Turkey Method is defined as "pure" detoxification, without using any medications. In cold Turkey, the person gives up the substance use all at once. That is, rather than gradually easing the process through reduction or by using replacement medication. Although a disadvantage of this method might be severe withdrawal symptoms [15], safety of this method has been shown [16]. Cold turkey is being used by people in many parts of the world [16-18].

For the first time, when the drug of use is heroin and the 115 method of abstinence is cold Turkey, this study aimed to document the changes in memory functioning following successful abstinence.

\section{Methods \\ 2.1. Design and Settings}

This study is a prospective study conducted in Tehran, Iran in 2008. Data collection was done in the drop-in-centers (therapeutic centers) of Tavalody Dobareh Rehabilitation Center, Tehran, Iran. This center is a non-governmental organization (NGO) for the treatment of substance use, especially opiates. It has treatment centers in 21 provinces out of the total 32 provinces of the country. This center is the most active center for the cold Turkey abstinence of opioids in Iran.

\subsection{Codes of Ethics}

All participants signed an informed consent. The ethical board of the National University of Malaysia approved the study.

\subsection{Participants and Sampling}

A total number of 30 participants with heroin dependence were enrolled. Drug dependence was defined according to the Diagnostic and Statistical Manual of Mental Disorders IV (DSM-IV) criteria [19-23]. To obtain a representative sample of all attendants of the Tavalody Dobareh Rehabilitation Center, we used a simple random sampling strategy from new entries. Each month, about 40 new patients are being recruited to the treatment, from these, most are men, and most are heroin dependents, and the most 
widely used treatment is cold Turkey. All new clients were given a 4 digit code which was used for sampling in this study. We selected the participants using computer generated random numbers.

\subsection{Procedure}

In this study, complete and successful drug abstinence was defined as the state of refraining from drug use completely (a drug free state) [24]. Here, successful abstinence was defined after 4 weeks of heroin abstinence.

\subsection{Measures and Measurements}

In this study, data were collected via interviews. All interviews were done by a single psychologist (SA). Data included socio-demographic data (gender, age, educational level, and marital status), drug use data (person who suggested for first use, first drug and substance) and overall health.

\subsection{Main Outcome}

The Wechsler Memory Scale (WMS) was also completed before and after complete abstinence. The WMS includes verbal and visual learning tests by means of association and matching, memory of excerpts, drawings and the identification of visual spatial information previously presented. Memory is assessed in terms of both immediate and delayed recall. The WMS provides global values for general, verbal and visual short- and long-term memory, as well as for attention and concentration. Specific functionality is evaluated in the verbal areas of logical memory and associative learning with verbal pairing (immediate and delayed) along with the visual areas of memory of image, learning associated with visual stimuli (immediate and delayed) and visual reproduction of pictures (immediate and delayed), as well as the areas of mental concentration, numeric span and visual memory. Comparison of the index of attention/concentration with the general index of memory on the WMS provides a means of distinguishing between disorders of concentration and those of memory. WMS is highly accurate at classifying severely impaired and unimpaired subjects in terms of memory but is less accurate at discriminating mild and moderate impairment [25-28].

\subsection{Statistical Analysis}

The paired samples t-test was used for data analysis to assess the effect of heroin abstinence on memory scores on personal information, orientation, mental control, logical memory, number repetition, visual memory, association learning and memory quotient. We used SPSS 14 for data analysis, and a level of $\mathrm{P}$ less than .05 was considered significant.

\section{Results}

Participants were all men. Table 1 shows sociodemographic and drug related characteristics

Table 1. Socio-demographic and drug related data $(\mathrm{n}=30)$

\begin{tabular}{|lc|}
\hline Participants Characteristics & N $(\%)$ \\
\hline Socio-demographic information & $30(100)$ \\
Gender (Male) & \\
\hline Age (Y) & $6(20)$ \\
$20-24$ & $9(30)$ \\
$30-34$ & $9(30)$ \\
Above 35 & $19(63.1)$ \\
Educational Level (High School Diploma or Less) & $4(13.3)$ \\
Marital Status (Married) & \\
Drug use information & $26(86.7)$ \\
Person Who Suggested First Use (Friend) & $21(70)$ \\
First Illicit Drug (Opium) & $30(100)$ \\
Perceived Health (Not healthy) & $19(63.3)$ \\
\hline First Substance (Cigarette) & \\
\hline
\end{tabular}

The paired $\mathrm{t}$ test showed that memory functioning subscales namely orientation, mental control, logical memory, number repetition, visual memory, association learning and memory quotient significantly improved after complete abstinence of heroin dependency. Personal information showed only a marginal significant improvement (Table 2).

Table 2. Comparison of memory function before and after heroin abstinence

\begin{tabular}{|c|c|c|c|}
\hline & Before & After & \\
\hline & Mean \pm SD $^{*}$ & Mean \pm SD & $\mathbf{P} * *$ \\
\hline Personal Information & $4.60 \pm 1.38$ & $5.00 \pm 1.05$ & .056 \\
\hline Orientation & $3.83 \pm 1.176$ & $4.76 \pm 0.50$ & $<.001$ \\
\hline Mental Control & $5.16 \pm 2.62$ & $6.43 \pm 1.79$ & .006 \\
\hline Logical Memory & $4.11 \pm 2.97$ & $7.76 \pm 2.83$ & $<.001$ \\
\hline Number Repetition & $7.60 \pm 3.02$ & $9.23 \pm 1.94$ & $<.001$ \\
\hline Visual Memory & $8.90 \pm 3.39$ & $10.66 \pm 2.83$ & $<.001$ \\
\hline Association Learning & $12.91 \pm 5.34$ & $15.23 \pm 3.58$ & .002 \\
\hline
\end{tabular}

Memory Quotient

** SD: Standard Deviation

\section{Discussion}

According to our findings, individuals with heroin dependence undergoing opioid withdrawal regimes unassisted by opioid substitution treatment or withdrawal symptom alleviation show improved memory function in multiple domains. Thus, complete abstinence from heroin dependence disorder may improve most areas of memory functions (i.e. orientation, mental control, logical memory, number repetition, visual memory, association learning and memory quotient) even when the method is cold Turkey.

This study adds to the literature regarding the effects of detoxifying opiate addicts on cognitive functioning [8], in the case of heroin [4]. The result of this study was unique as heroin was the drug of dependence and cold Turkey was the method of abstinence. We could not find any previous similar studies.
Literature has shown that patients at entry of opiate detoxification programs present with cognitive impairments to varying degrees of severity [7]. Opiate abusers show impaired neuropsychological functioning in comparison to matched controls with no history of drug abuse [10]. Both methadone- and buprenorphine-treated opioid-dependent patients frequently show cognitive deficits in attention, working memory, and verbal memory [12]. According to another study, memory performance of drug users in the abstinence fell between patients under methadone maintenance and controls on many measures suggesting that methadone maintenance may reduce cognitive impairment associated with long-term drug abuse, and some early recovery of neurocognitive functioning may occur during abstinence [29]. The same finding has been reported for other drugs such as cocaine [30]. 
Studies have reported possible mechanisms for the link between memory dysfunction and drug use from which, one is a possible link between cerebral perfusion abnormalities and neuropsychological impairment following chronic substance abuse [31].

New information regarding improvement of memory following drug use treatment has implications for drug abuse treatment policies and practices [32]. Thus, the result of our preliminary study is indicative of benefits of heroin dependence treatment programs that use the cold Turkey method. We already know that memory improvement increases the efficacy of opioid treatment programs [3-6]. Thus, the results may contribute to reducing burden of drug use in Iran [33-41].

\section{Conclusion}

In sum, abstinence of heroin using cold Turkey method may improve memory functioning. Further controlled studies are needed in this regard.

\section{Limitations}

Our study had a few limitations. In addition to lack of a control group, it had a small sample size. Physical or psychological health may have confounded the effect of the program on memory functioning in our study. A controlled study is needed to control for the effect of such confounders.

\section{Acknowledgements}

Many thanks to the National University of Malaysia and also Tavalody Dobareh Rehabilitation Center, Tehran, Iran.

\section{Authors' Contributions}

Sepideh Aryanfard designed the study, collected the data, and ran the statistical analysis. Rozainee Khairudin and Yahaya Mahamood served on the dissertation committee and advised Sepideh Aryanfard, and contributed to the design. Shervin Assari contributed to the design, writing, and revision. All authors approved the final version of the manuscript.

\section{Financial Disclosure}

None.

\section{Funding/Support}

This study was the result of a dissertation in the National University of Malaysia.

\section{References}

1. Covin R, Donovan LA, MacIntyre PD. The relationship between selfestem and performance when information regarding others' performance is available. J Soc Psychol. 2003;143(4):541-4.

2. Tiggemann $\mathbf{M}$. The impact of adolescent girls' life concerns and leisure activities on body dissatisfaction, disordered eating, and selfesteem. J Genet Psychol. 2001;162(2):133-42.

3. Avants SK, Margolin A, Mckee S. A path analysis of cognitive, affective, and behavioral predictors of treatment response in a methadone maintenance program. J Subst Abuse. 2000;11(3):215-30.

4. Verdejo A, Toribio I, Orozco C, Puente KL, Pérez-García M. Neuropsychological functioning in methadone maintenance patients versus abstinent heroin abusers. Drug Alcohol Depend. 2005;78(3):283-8.

5. Faggiano F, Vigna-Taglianti FD, Versino E, Zambon A, Borraccino A, Lemma P. School-based prevention for illicit drugs use: a systematic review. Prev Med. 2008;46(5):385-96.

6. Buckman JF, Bates ME, Morgenstern J. Social support and cognitive impairment in clients receiving treatment for alcohol- and drug-use disorders: a replication study. J Stud Alcohol Drugs. 2008;69(5):73846.
7. Streel E, Antoniali V, Campanella S, Castronovo J, Hanak C, Pelc I Verbanck P. Evaluation of cognitive functioning in 101 patients before opiate detoxification: implications in setting up therapeutic strategies. J Opioid Manag. 2005;1(1):49-53.

8. Curran HV, Kleckham J, Bearn J, Strang J, Wanigaratne S. Effects of methadone on cognition, mood and craving in detoxifying opiate addicts: a dose-response study. Psychopharmacology (Berl). 2001;154(2):153-60.

9. Darke S, Sims J, McDonald S, Wickes W. Cognitive impairment among methadone maintenance patients. Addiction. 2000;95(5):68795

10. Davis PE, Liddiard H, McMillan TM. Neuropsychological deficits and opiate abuse. Drug Alcohol Depend. 2002;67(1):105-8.

11. Lyvers M, Yakimoff M. Neuropsychological correlates of opioid dependence and withdrawal. Addict Behav. 2003;28(3):605-11.

12. Rapeli P, Fabritius C, Alho H, Salaspuro M, Wahlbeck K, Kalska H. Methadone vs. buprenorphine/naloxone during early opioid substitution treatment: a naturalistic comparison of cognitive performance relative to healthy controls. BMC Clin Pharmacol. 2007;7:5.

13. Specka M, Finkbeiner T, Lodemann E, Leifert K, Kluwig J, Gastpar M. Cognitive-motor performance of methadone-maintained patients. Eur Addict Res. 2000;6(1):8-19.

14. Prosser J, Cohen LJ, Steinfeld M, Eisenberg D, London ED, Galynker II. Neuropsychological functioning in opiate-dependent subjects receiving and following methadone maintenance treatment. Drug Alcohol Depend. 2006;84(3):240-7

15. Gossop M, Battersby M, Strang J. Self-detoxification by opiate addicts. A preliminary investigation. Br J Psychiatry. 1991;159:20812.

16. Mańkowski W, Sikorski M. "Cold turkey" detoxification of drug, narcotic and chemical addicts conducted at the Occupational Diseases and Toxicology Ward of the Polish Center of Occupational Medicine in Poznan in 1986-1996. Przegl Lek. 1997;54(6):474-6. Polish.

17. Aldhous P. Drug rehabilitation: cold turkey, Vietnamese style. Nature. 2005;433(7026):568-9.

18. Munro R. Cod and cold turkey. Nurs Times. 1999;95(24):14-5.

19. Schuckit MA, Daeppen JB, Danko GP, Tripp ML, Smith TL, Li TK, et al. Clinical implications for four drugs of the DSM-IV distinction between substance dependence with and without a physiological component. Am J Psychiatry. 1999;156(1):41-9.

20. Baer JS, Ginzler JA, Peterson PL. DSM-IV alcohol and substance abuse and dependence in homeless youth. J Stud Alcohol. 2003;64(1):5-14.

21. Compton WM, Cottler LB, Dorsey KB, Spitznagel EL, Mager DE. Comparing assessments of DSM-IV substance dependence disorders using CIDI-SAM and SCAN. Drug Alcohol Depend. 1996;41(3):179-87.

22. Deas D, Roberts J, Grindlinger D. The utility of DSM-IV criteria in diagnosing substance abuse/dependence in adolescents. J Subst Use. 2005;10(1):10-21.

23. Fulkerson JA, Harrison PA, Beebe TJ. DSM-IV substance abuse and dependence: are there really two dimensions of substance use disorders in adolescents?. Addiction. 1999;94(4):495-506.

24. McKeganey N, Bloor M, Robertson M, Neale J, MacDougall J. Abstinence and drug abuse treatment: Results from the Drug Outcome Research in Scotland study. Drugs Educ pre policy. 2006;13(6):537-50.

25. D'Elia L, Satz P, Schretlen D. Wechsler Memory Scale: a critical appraisal of the normative studies. J Clin Exp Neuropsychol 1989;11(4):551-68

26. Wechsler D. A Standardized Memory scale for clinical use. Journa of psychology. 1945;1:87-95.

27. Howard AR. Further validation studies of the Wechsler Memory Scale. J Clin Psychol. 1954;10(2):164-7.

28. Makatura TJ, Lam CS, Leahy BJ, Castillo MT, Kalpakjian CZ Standardized memory tests and the appraisal of everyday memory. Brain Inj. 1999;13(5):355-67.

29. Mintzer MZ, Stitzer ML. Cognitive impairment in methadone maintenance patients. Drug Alcohol Depend. 2002;67(1):41-51.

30. Cunha PJ, Nicastri S, Gomes LP, Moino RM, Peluso MA. Neuropsychological impairments in crack cocaine-dependent inpatients: preliminary findings. Rev Bras Psiquiatr. 2004;26(2):1036.

31. Browndyke JN, Tucker KA, Woods SP, Beauvals J, Cohen RA, Gottschalk PC, et al. Examining the effect of cerebral perfusion abnormality magnitude on cognitive performance in recently abstinent chronic cocaine abusers. J Neuroimaging. 2004;14(2):1629. 
32. Lindholst C, Andreasen MF, Kaa E. Narcotics and illicit drug market. Status and 10-year development. Ugeskr Laeger. 2008;170(1):54-7.

33. Assari S, Lankarani MM, Dejman M, Farnia M, Alasvand M, Sehat M, Roshanpazooh M, Tavakoli M, Jafari F, Ahmadi K. Drug Use among Iranian Drivers Involved in Fatal Car Accidents. Front Psychiatry. 2014;5:69.

34. Assari S, Yarmohamadivasel M, Lankarani MM, Sehat M, Narenjiha M, Rafiey H, Noori R, Shirinbayan P, Ahmadi K. Having Multiple Sexual Partners among Iranian Intra-Venous Drug Users. Front Psychiatry. 2014;5:125

35. Assari S, Yarmohmmadi Vasel M, Tavakoli M, Sehat M, Jafari F, Narenjiha H, Rafiey H, Ahmadi K. Inconsistent Condom Use among Iranian Male Drug Injectors. Front Psychiatry. 2013;4:181.

36. Assari S, Ahmadi K, Rezazade M. Socio-Economic Status Determines Risk of Receptive Syringe Sharing Behaviors among Iranian Drug Injectors; A National Study Front Psychiatry. 2014;5:194.
37. Karimi M, Ghaheri H, Assari S, Ahmadi K, Lankarani MM, Lankarani RM, Narenjiha H, Rafiey H, Tavakoli M, Jafari M. Drug Injection to Sites other than Arm: A Study of Iranian Heroin Injectors. Front Psychiatry. 2014;5:23.

38. Rafiey H, Narenjiha H, Shirinbayan P, Noori R, Javadipour M, Roshanpajouh M, Samiei M, Assari S. Needle and syringe sharing among Iranian drug injectors. Harm Reduct J. 2009;6:21.

39. Ahmadi K, Rezazade M, Nafarie M, Moazen B, Yarmohmmadi Vasel M, Assari S. Unprotected Sex with Injecting Drug Users among Iranian Female Sex Workers: Unhide HIV Risk Study. AIDS Res Treat. 2012;2012:651070.

40. Daneshmandan N, Narenjiha H, Tehrani K, Assari S, KhoddamiVishteh HR. Initiation to the first drug use among substancedependent persons in Iran. Subst Use Misuse. 2011;46(9):1124-41.

41. Khooshabi K, Ameneh-Forouzan S, Ghassabian A, Assari S. Is there a gender difference in associates of adolescents' lifetime illicit drug use in Tehran, Iran? Arch Med Sci. 2010. 30;6(3):399-406. 